\title{
An explorative study in to the role of personality traits and stressful life events in acute and transient psychotic disorders
}

\section{Introduction}

Though there were several descriptions of 'Third Psychosis' from across the world, ${ }^{1,2}$ Acute and Transient Psychotic Disorder(ATPD) is a new entity in ICD, first introduced in 1992 . Some researchers points out that vulnerable personality makes a person prone to psychotic breakdown when challenged with stressful life situation ${ }^{4-5}$ Though ICD 10 considers the traditional association of ATPD with stress and provide it as one among 3 key features, it also states that ATPD can occur without stress. Though 'vulnerable personality' is a common notion, there is no mention about personality in ICD 10 F23. Hence this study which aims at whether stress need to be always associated with ATPD as a preceding factor and whether personality traits of ATPD patients differ significantly from age and gender matched controls.

\section{Subjects and methods}

Study period- $1^{\text {st }}$ May 2015 to $30^{\text {th }}$ April 2016

Type of study: Descriptive Study (Questionnaire based)

Cases were recruited only from in patient settings. All patients who were admitted with psychosis during study period and with a final diagnosis of ATPD, made by consultant psychiatrist based on ICD $10 \mathrm{DCR}$, were considered for the study. They were taken in after confirmed to be symptom free by the consultant during the follow up in first and second week after discharge. As controls, the person accompanying the patient to hospital for follow up -not necessarily relatives- who were not having any past history of psychiatric disorders were selected after matching for age and gender in equal number as the cases.

Inclusion criteria:

a. Age between 18 and 65

b. Those giving consent for the study

c. Minimum of pre degree/ plus 2 education and knowing to read and understand English.

Exclusion criteria were:

a) Presence of organic mental disorder, learning disabilities or mental retardation

b) Patients not coming for follow up

c) Patients having residual psychotic symptoms even after 1 month of onset of symptoms

\section{Tools}

Socio-demographic profile was collected using a specifically designed Performa.

Stressful life events were rated using Presumptive Stressful Life
Volume 9 Issue 3 - 2018

\begin{abstract}
Poulose Merin, Antony JT, K Praveenlal
Department of Psychiatry, Jubilee Mission Medical College \& Research Institute, Kerala University of Health Sciences, India
\end{abstract}

Correspondence: Praveenlal K, Professor of Psychiatry \& Principal, Jubilee Mission Medical College \& Research Institute, Thrissur, Kerala, India, Tel +919895647935, Email drpraveenlalkuttichira@gmail.com

Received: April 08, 2018 | Published: May 31, 2018

Event Scale (PSLE). It is a respondent based method and was widely used in Indian settings.

Personality traits were measured using NEO FFI. Originally devised by Paul Costa \& Robert McCrae, ${ }^{10}$ it is a self-rating questionnaire - validated, ${ }^{10}$ reliable ${ }^{11}$ and with internal consistency. ${ }^{10}$ It comprises of 60 questions, to be responded on a Likert scale. The responses are then scored for the big five factors. Statistical analysis was performed using the Statistical Package for Social Sciences (SPSS) Version 22.Mean and Standard deviation (SD) determined for the personality traits. Independent sample $t$ test done and significance was assumed if $\mathrm{p}=<0.05$.

\section{Results}

A total of 56 patients were admitted in the ward during the study period with a provisional diagnosis of acute onset psychosis. Eight patients did not come for follow up. 23 patients were excluded from the study due to persisting psychotic features during follow up. Three patients were excluded as they didn't meet the educational qualification of the inclusion criteria. There were 22 patients during the study period who were meeting the inclusion criteria as cases. Controls were selected in equivalent numbers after matching for age and gender. The mean score obtained for each of the five personality traits for mentally healthy controls in this study (Table 1) were comparable with the mean scores of normal population obtained in the study ${ }^{12}(n=1492)$ conducted by developers of the tool .

Of the cases meeting the inclusion-exclusion criterias, majority were females. Majority of patients were in third and fourth decade of their life (Table 2). Mean age was 35.35 years for cases and 35.25 years for controls with a standard deviation of 9.66 and 10.21 respectively. $82 \%$ of cases were educated up to Predegree $\left(12^{\text {th }} \mathrm{Std}\right)$ or equivalent while $18 \%$ were graduates or postgraduates (Table 2) 19 patients (86.36\% of cases) had preceding stress factors while three cases and none of the controls reported any stress enlisted in PSLE scale. The mean score of stress was 49.75 ( $\mathrm{SD}=18.90)$ (Table 3) Comparing the scores obtained for each of the 5 traits, scores for Neuroticism and Conscientiousness were found to be significantly 
different for cases from controls (Table 4). Mean score of neuroticism for cases was found to be significantly less than controls. Mean scores of conscientiousness of cases was found to be significantly higher than controls. Statistical significance was highest for the difference in scores of neuroticism between cases and controls with $\mathrm{p}=0.0001$. The difference in conscientiousness was also statistically significant, but less than that for neuroticism (Table 4).

Table I Mean scores of controls compared to scores of normal individuals in a large sample study ${ }^{\prime 2}$

\begin{tabular}{lllll}
\hline & $\begin{array}{l}\text { Mean in } \\
\text { reference } \\
\text { study }\end{array}$ & $\begin{array}{l}\text { SD in } \\
\text { reference } \\
\text { study }\end{array}$ & $\begin{array}{l}\text { Mean in } \\
\text { present } \\
\text { study }\end{array}$ & $\begin{array}{l}\text { SD in } \\
\text { present } \\
\text { study }\end{array}$ \\
\hline Neuroticism & 24.65 & 8.07 & 24 & 6.655 \\
Extraversion & 28.5 & 6.26 & 27.32 & 3.981 \\
Openness & 28.4 & 6.57 & 24.82 & 3.39 \\
Agreeableness & 28.31 & 6.34 & 26.05 & 3.897 \\
Conscientousness & 27.45 & 7.3 & 29.27 & 5.824
\end{tabular}

Table 2 Demographic characteristics of patients and controls

\begin{tabular}{lllllll}
\hline & & Patient & Control & $\begin{array}{l}\text { Significance } \\
\text { Chi square } \\
\text { test }\end{array}$ \\
\hline Sex & Male & 7 & $32 \%$ & 7 & $32 \%$ & Value $=0$ \\
& Female & 15 & $68 \%$ & 15 & $68 \%$ & \\
Age & $20-29$ & 7 & $32 \%$ & $7 *$ & $32 \%$ & Value=0 \\
& $30-39$ & 9 & $41 \%$ & 9 & $41 \%$ & \\
& $40-49$ & 4 & $18 \%$ & 4 & $18 \%$ & \\
Educational & $\begin{array}{l}\text { Status } \\
\text { PDCl+2 }\end{array}$ & 18 & $82 \%$ & 17 & $77 \%$ & Value=8.I \\
& $\begin{array}{l}\text { Degree/ } \\
\text { above }\end{array}$ & 4 & $18 \%$ & 5 & $23 \%$ & \\
\hline
\end{tabular}

Table 3 Characteristics of stress in patients and controls

\begin{tabular}{llll}
\hline Stress & Total & Patient & Control \\
\hline Present & 19 & 19 & 0 \\
Absent & 25 & 3 & 22 \\
PSLE & & Mean Score $=49.75 ;$ SD 18.91 & Mean score $=0$
\end{tabular}

Table 4 Five factor score for patients and controls

\begin{tabular}{llllll}
\hline & Group & N & Mean & SD & P value \\
\hline \multirow{2}{*}{ Neuroticism } & Case & 22 & 17.05 & 5.159 & \\
& Control & 22 & 24 & 6.655 & 0.0001 \\
Extroversion & Case & 22 & 27.09 & 7.091 & \\
& Control & 22 & 27.32 & 3.981 & 0.896 \\
Openness & Case & 22 & 24.82 & 7.035 & \\
& Control & 22 & 24.82 & 3.39 & \\
Agreeableness & Case & 22 & 28.36 & 6.028 & \multirow{2}{*}{0.137} \\
& Control & 22 & 26.05 & 3.897 & \\
Conscientiousness & Case & 22 & 36.77 & 8.326 & \multirow{2}{*}{0.001} \\
& Control & 22 & 29.27 & 5.824 & \\
\hline
\end{tabular}

\section{Discussion}

ATPD -first introduced in ICD 10- faces many challenges about its existence due to lack of prognostic stability. ${ }^{13}$ Working Group on classification of Psychiatric Disorders (WGPD) recommends retaining the diagnosis of ATPD in ICD1114 with focus on its sudden onset, brief duration and polymorphic presentation. ${ }^{14}$ The present study supports its existence qualifying ICD10 criteria for ATPD. Based on Allport's definition of personality, the 171 fundamental traits compiled by him were reduced to 16 basic dimensions by Reymond Catell. In recent years, Robert McCrae \& Paul Costa ${ }^{16}$ used factor analysis to arrive at five higher order traits. ${ }^{15,16}$ This has become the dominant concept of personality structure in contemporary psychology. ${ }^{17}$ These five traits have been characterized as the "latitude and longitude" along which personality could be mapped. ${ }^{18}$ Controls in this present study matched in the scores of their personality traits with previous studies using the same tool from different parts of the world, ${ }^{10-13,19-21}$ including large sample community based original study. ${ }^{12}$ This shows that the tool is culture free, can be used anywhere and give standard result in our region also. There is a female predominance in our sample in agreement with other hospital based studies, ${ }^{22-26}$ but not in accordance with community based studies ${ }^{27,28}$ where the pattern is that of male preponderance. This disparity could be due to greater number of females being brought to clinical attention. However no firm conclusions could be drawn due to small sample size from a single centre. Various studies have reported higher frequency of stress prior to the onset of acute psychosis. ${ }^{22,23}$ It is also observed that first episode psychosis patients are strikingly more likely to report an intrusive event in the three months before the onset. ${ }^{29}$ According to Varma et al. ${ }^{24}$ all the subjects experienced stressful events prior to onset of psychosis. Das et al., ${ }^{30}$ tested this again in ATPD patients and supported the same. Malhotra et al., ${ }^{25}$ and ICMR (Indian Council Of Medical Research) psychosis study ${ }^{27}$ observed preceding stress in $60 \%$ and $50 \%$ of those having ATPD, respectively. There are recent observations from Chandigarh 2 that stress is a major predisposing factor in the evolution of ATPD. But across studies the actual proportion of patients who experienced acute stress in the time frame varied considerably ranging from $10 \%-69 \% 31$. ICD itself mentions stress as a specifier that there could be cases without stress. ${ }^{3}$ Mehta et al., ${ }^{32}$ noted that there are no precipitating stressful factors in most cases after a retrospective study on 185 patients. Our study supports those Indian studies showing the presence of acute stress in patients having ATPD. The occurrence of ATPD without stressors in a few patients signifies that stress is not essential for the development of illness. Hence, the importance of stress as a specifier in $\mathrm{ICD}^{10}$ is endorsed by the present study also. Though the concept of "vulnerable personality" is a common notion, there is no mention about personality in the concept of ATPD in ICD. ${ }^{10}$ There are observations that people who are emotionally labile, easily impressed, having a tendency to disproportionate reaction and with fragile personality characteristics are more prone to develop ATPD. ${ }^{7-9}$ Chavan \& Kulhara $^{5}$ found out that subjects with acute psychosis (whether ATPD or Schizophrenia or manic depressive psychosis) have suspiciousness and cyclothymic traits in their personality. On the other hand, Jorgensen ${ }^{6}$ have explained that, in $37 \%$ of ATPD patients, no personality disorder could be found and it is not related to any specific personality disorder. There are recent studies ${ }^{33}$ that used NEO FFI stating that personality of patients with ATPD does not differ from general population. In our study, it was found that those who had ATPD have significantly lower neuroticism and there was prominent presence of conscientiousness in them. This contradicts the existing 
study ${ }^{33}$ which used the same tool. Reason for contradictions need to be explored further. Assuming that our findings stand valid, it could be hypothesised that, those with neuroticism achieve conflict resolution using their set of defence mechanisms, thereby averting psychotic breakdown. The presence of a high conscientiousness in the presence of stress in those who have low neuroticism lead to psychosis in ATPD. Also in this study, it is found that the pattern of personality trait of those with ATPD (low neuroticism \& high conscientiousness) is the opposite of the personality traits of schizophrenia and their first degree relatives(high neuroticism \& low conscientiousness) as found in study by Gurrera et al. ${ }^{19}$ Maier et al. ${ }^{20}$ and Tien et al. ${ }^{21}$ So whether the personality trait has any contribution in making ATPD transient has to be studied further.

\section{Conclusion}

Similar to stress, presence of low neuroticism and high conscientiousness can be vulnerability factors, for the development of ATPD. The pattern of personality traits according to Five Factor Model for a person with transient psychosis is diametrically opposite to the pattern in longstanding psychosis.

\section{Limitations of the study}

Ours was not a community based study, sample size was small and the tools used were self-respondent based. Hence generalisation is not possible.

\section{Acknowledgements}

We acknowledge the contribution by Dr. Neethi Valsan MD, Dr.Girish Menon DNB, Consultant Psychiatrists, Mr. Tom Thomas, Biostatistician, Jubilee Mission Medical College, Thrissur, Kerala, India.

\section{Conflict of interest}

The author declares that there is no conflict of interest.

\section{References}

1. Andreas Marneros. Beyond the Kraepelinian dichotomy: acute and transient psychotic disorders and the necessity for clinical differentiation. Br J Psychiatry. 2006;189:1-2.

2. Savita Malhotra. Acute and Transient Psychosis: A Paradigmatic approach. Indian J Psychiatry. 2007;49(4):233-243.

3. World Health Organization. The ICD 10 Classification of Mental and Behavioural Disorders. Diagnostic Criteria for Research. Geneva: World Health Organization;1993.

4. Kapur RL, Pandurangi AK. A comparative study of reactive psychosis and acute psychosis without precipitating stress. British Journal of Psychiatry. 1979;135(6):544-550.

5. Chavan BS, Kulhara P. A clinical study of reactive psychoses. Acta Psychiatrica Scandinavica. 1988;78:712-715.

6. Jorgensen P, Bennedsen B, Christensen J, et al. Acute and Transient Psychotic disorder: comorbidity with personality disorder Acta Psychiatr Scand. 1996;94(6):460-464.

7. Pichot P. A comparison of different national concepts of schizoaffective psychosis. In: AMarneros, MT Tsuang, editors. Schizoaffective Psychoses. Berlin, Heidelberg: Springer; 1986.
8. Stromgren E. Reactive (psychogenic) psychoses and their relations to schizoaffective psychoses. In: A Marneros, MT Tsuang, editors. SchizoaffectivePsychoses. Berlin, Heidelberg: Springer; 1986:260-271.

9. Ungvari GS, Mullen PE. Reactive psychoses revisited. Aust $N Z J$ Psychiatry. 2000;34(3):458-467.

10. Costa PT, McCrae RR. Revised NEO Personality Inventory (NEOPI-R) and NEO Five-Factor Inventory (NEO-FFI). Odessa, FL: Psychological Assessment Resources; 1992.

11. Robins RW, Fraley, Roberts RC, et al. A longitudinal study of personality change in young adulthood. J Pers. 2001;69(4):617-640.

12. Robert R McCrae, Paul T. A contemplated revision of the NEO Five Factor Inventory. Personality and Individual Differences. 2004;36(3):587-596.

13. Swaran P Singh, Tom Burns, Shazad Amin, et al. Acute and transient psychotic disorders: precursors, epidemiology, course and outcome. $\mathrm{Br} J$ Psychiatry. 2004;185:452-459.

14. Wolfgang Gaebel, Jurgen Zielasek, Helen-Rose Cleveland. Psychotic disorders in ICD-11. Asian Journal of Psychiatry. 2013;6(3):263-265.

15. Costa PT, McCrae RR. Revised NEO Personality Inventory (NEOPI-R) and NEO Five-Factor Inventory (NEO-FFI). Odessa, FL: Psychological Assessment Resources; 1992.

16. Robert $\mathrm{R}$ McCrae, Paul $\mathrm{T}$ Costa. A contemplated revision of the NEO Five Factor Inventory. Personality and Individual Differences. 2004;36(3):587-596.

17. John OP, Srivasthava S. The Big Five Trait Taxonomy: History, measurement and theoretical perspectives. In: LA Pervin \& OP John, editors. Handbook of Personality: Theory and Research. New York: Guilford press; 1999:102-138.

18. D Jozer, SP Reise. Personality Assessment. Annual Review of Psychology. 1994;45(1):357-388.

19. Gurrera RJ, Nestor PG, O’Donnell BF. Personality traits in schizophrenia:comparison with a community sample. J Nerv Ment Dis. 2000;188(1):31-35.

20. Maier W, Minges J, Lichtermann D. Personalityvariations in healthy relatives of schizophrenics. Schizophrenia Research. 1994;12:81-88.

21. Tien AY, Costa PT, Eaton WW. Covariance of personality, neurocognition, and schizophrenia spectrum traits in the community. Schizophr Res. 1992;7(2):149-158

22. Malhotra S, Varma VK, Misra AK, et al. Onset of acute psychotic states in India; a study of sociodemographic, seasonal and biological factors. Acta Psychiatrica Scandinavica. 1998;97:125-131.

23. Susser E, Varma VK, Malhotra S, et al. Delineation of acute and transien psychotic disorders in a developing country setting. Br J Psychiatry. 1995;167(2):216-219.

24. Varma VK, Malhotra S, Jiloha RC. Acute non organic psychotic states in India- Symptomatology. Indian Journal of Psychiatry. 1992;34:89-101.

25. Malhotra S, Malhotra S. Acute and transient psychosis: Conceptual understanding and current status. In: Murthy RS, editor. Mental Health in India 1950-2000. Bangalore: PAMH; 2001:49(4):17-41.

26. Susser E, Fennig S, Jandorf L, et al. Epidemiology, diagnosis and course of brief psychoses. Am J Psychiatry. 1995;152(12):1743-8.

27. Indian Council of medical Research. Final report of phenomenology and natural history of acute psychosis. New Delhi: ICMR; 1985.

28. Collins PY, Varma VK, Wig NN, et al. Fever and acute brief psychosis in urban and rural settings in north India. Br J Psychiatry. 1999;174:520-4. 
29. Raune D, Kuipers E, Bebbington P. Stressful and intrusive life events preceding first episode psychosis. Epidemiol Psichiatr Soc. 2009;18(3):221-8.

30. Das SK, Malhotra S, Basu D. Testing the stress vulnerability hypothesis in ICD 10 diagnosed acute and transient psychotic disorders. Acta Psychiatrica Scandinavica. 2001;104:56-58.

31. Laura J Fochtmann, Ramin Mojtabai, Evelyn J Bromet. Other Psychotic Disorders; Comprehensive Textbook of Psychiatry. Ninth Edition.
32. S Mehta, A Tyagi, MK Swami, et al. Onset of acute and transient psychotic disorder in India: A study of sociodemographics and factors affecting its outcomes. East Asian Arch Psych. 2014;24(2):75-80.

33. Pillmann F, Bloink R, Balzuweit S, et al. Personality and social Interactions in patients with acute brief psychoses. $J$ Nerv Ment Dis. 2003;191(8):503-8. 